\title{
Correction to: Residual Stress Distributions in Cold-Sprayed Copper 3D-Printed Parts
}

\author{
Rebecca Sinclair-Adamson ${ }^{1}$ Vladimir Luzin ${ }^{2,3}$ • Andrew Duguid ${ }^{4}$. \\ Krishnan Kannoorpatti ${ }^{1} \cdot$ Rebecca Murray $^{1}$
}

Published online: 20 November 2020

(C) ASM International 2020

\section{Correction to: J Therm Spray Tech (2020) 29:1525-1537 https://doi.org/10.1007/s11666-020- 01040-7}

In the introduction section, the last sentence of the first paragraph should be read as follows:

"Presently, there are several modular CSAM systems on the market (Ref 4-8)."

In place of:

"Presently, there are several commercial CSAM systems on the market including modular units made by SPEE3D (Ref 4, 5) and Titomic (Ref 6-8). SPEE3D machines are geared towards freeform components, whereas Titomic machines typically produce axisymmetric components."

In addition, the authors declare the following interests related to the work:

- The research leading to these results received funding from Cooperative Research Centres Projects under Grant Agreement No CRC-P57355 "Breaking the

The original article can be found online at https:// doi.org/10.1007/s11666-020-01040-7.

Rebecca Murray

rebecca.murray@cdu.edu.au

1 Advanced Manufacturing Alliance, Charles Darwin University, Ellengowan Drive, Casuarina, NT 0810, Australia

2 Australian Nuclear Science and Technology Organization, Lucas Heights, NSW 2234, Australia

3 School of Engineering, The University of Newcastle, Callaghan, NSW 2308, Australia

4 SPEE3D, Dandenong, VIC 3175, Australia
Mould: Making Australian Advanced Manufacturing Portable" whose project partners are: Effusiontech Pty Ltd, Charles Darwin University and PW Baxter \& Associates Pty Ltd. The research leading to these results also received funding from Australian Nuclear Science and Technology Organization under proposal ID 7104.

- The Advanced Manufacturing Alliance at Charles Darwin University (CDU) is an alliance that was set up with founding member SPEE3D. Authors Rebecca Sinclair-Adamson and Rebecca Murray receive salary from CDU through grant agreement CRC-P57355.

- Author Vladimir Luzin receives salary from Australian Nuclear Science and Technology Organization.

- Author Andrew Duguid receives salary from SPEE3D.

- Author Krishnan Kannoorpatti receives salary from CDU (not funded through CRC-P57355).

- Author Rebecca Murray has a shareholding in SPEE3D.

Publisher's Note Springer Nature remains neutral with regard to jurisdictional claims in published maps and institutional affiliations. 